\title{
DOAÇÃO DE ÓRGÃOS SOB A ÓPTICA DO ESTUDANTE UNIVERSITÁRIO
}

\author{
Organ Donation Under University Students' Point of View
}

\author{
Zélia Maria de Sousa Araújo Santos', Arícia Pereira Capistrano², Vera Lúcia Mendes Oliveira³, João David de Souza Neto ${ }^{4}$
}

\section{RESUMO}

Objetivo: Conhecer a opinião dos estudantes universitários sobre a doação de órgãos. Método: Estudo exploratório-descritivo, realizado numa universidade privada, com 269 estudantes de idade igual ou superior a 18 anos. Resultado: Constatou-se que a maioria (70\%) dos estudantes tinha idade variando entre 18 a 23 anos. Houve predomínio $(68 \%)$ de estudantes do sexo feminino. Observou-se que a maioria $(78 \%)$ da amostra pesquisada mostrou-se favorável à doação de órgãos, e que $25 \%$ tinham dúvidas sobre este assunto. Quanto às sugestões, $66 \%$ dos entrevistados indicaram campanhas para um melhor esclarecimento sobre o assunto e conscientização da população sobre a importância da doação de órgãos. Conclusão: Conclui-se que havia um desconhecimento significativo da clientela investigada sobre o processo de doação de órgãos.

Descritores: doação de órgãos e tecidos, legislação dos transplantes, opinião na doação de órgãos e tecidos.

Trabalho realizado na Unidade de Transplante e Insuficiência Cardíaca do Hospital de Messejana - UTIC - Av. Frei Cirilo, s/nº - Cajazeiras - Fortaleza - Cear - CEP 60000-000.

1. Enfermeira. Doutora em enfermagem. Coordenadora de equipe multidisciplinar da Unidade de Transplante e Insuficiência Cardíaca do Hospital de Messejana -UTIC. Fortaleza-Ceará;

2. Enfermeira da Unidade Básica de Saúde. Especialista em Saúde da Família. Fortaleza-Ceará;

3. Doutora em Enfermagem. Enfermeira da Unidade de Transplante e Insuficiência Cardíaca do Hospital de Messejana - UTIC. Fortaleza-Ceará;

4. Médico. Especialista em Cardiologia. Coordenador Médico da Unidade de Transplante e Insuficiência Cardíaca do Hospital de Messejana - UTIC. Fortaleza - Ceará.

Endereço para correspondência: Zélia Maria de Sousa Araújo Santos - Rua Gonçalves Ledo, 1635 - Aldeota - Fortaleza - Ceará - CEP 60 110-261 - FAX: (85) 32511555 - Tel: (85) 9982-8358 - E-mail: zeliasantos@unifor.br

Recebido em: 26/08/04 Aceito em: 29/04/05

\section{INTRODUÇÃO}

A Lei no. 9434/97, também conhecida como Lei dos Transplantes, trata das questões da disposição post mortem de tecidos, órgãos e partes do corpo humano para fins de transplante; dos critérios para transplante com doador vivo e das sanções penais e administrativas pelo não cumprimento da mesma. O Art. $4^{\circ}$, dessa lei, dispõe que "salvo manifestação de vontade em contrário, nos termos desta lei, presume-se autorizada a doação de tecidos, órgãos ou partes do corpo humano, para finalidade de transplantes ou terapêutica post mortem". Este artigo foi modificado pela Medida Provisória $\mathrm{n}^{\mathrm{o}} 1718 / 98$, que determina a necessidade de autorização familiar, colocando-a como poder supremo do ato de doar. ${ }^{1}$

A partir desta data, houve intensos debates envolvendo pessoas e instituições, a fim de promover ampla reflexão sobre essa lei, na mídia e em grupos sociais, com a finalidade de esclarecer a população sobre doação e transplantes e a nova lei que os rege, porém, o resultado tem sido insuficiente, a doação de órgãos ainda é muito limitada em nosso meio, bem como o número de transplantes. Como conseqüência, está ocorrendo a hipertrofia da lista de candidatos ou receptores de órgãos. Possivelmente, os fatores desencadeantes desta limitação estejam relacionados com o déficit de conhecimento da sociedade sobre o processo de doação, despreparo dos profissionais para manter os órgãos viáveis para transplantes e estrutura inadequada das instituições no processo de captação de órgãos.

Estima-se que somente de 1 a $4 \%$ das pessoas que morrem em hospital, e de 10 a $15 \%$ daquelas que morrem em unidades de cuidados intensivos apresentam quadro de morte encefálica, sendo, portanto, potenciais doadores. Desses potenciais doadores, somente 15 a $67 \%$ tornam-se doadores efetivos, devido a não detecção e/ou não notificação da morte encefálica; ou às contra-indicações médicas ou problemas na manutenção do doador cadáver em 15 a 
$40 \%$ dos casos ou, ainda, em razão da recusa familiar à doação em $20 \%$ das situações. Atualmente, a obtenção de órgãos de doadores cadáver não atende à demanda na quase totalidade dos países que realizam transplantes. ${ }^{2}$

Morte encefálica é a perda irreversível da capacidade para ter consciência, associada à irreversível perda da capacidade de respirar. Devendo ser enfatizada a irreversibilidade do processo e a total incompatibilidade com a vida fora do suporte mecânico respiratório. ${ }^{3}$

A doação de órgãos pressupõe critérios de seleção como a idade, o diagnóstico que levou à morte e o tipo sangüíneo, que são itens estudados do provável doador, para saber se há receptor compatível. Não existe restrição absoluta à doação de órgãos a não ser para doentes com AIDS e pessoas com doenças infecciosas ativas. Em geral, fumantes não são doadores de pulmão. ${ }^{4}$

No Brasil, nas últimas décadas, desenvolveu-se uma notável capacidade técnica para várias modalidades de transplante. No entanto, o aprimoramento tecnológico convive com questões de natureza sociocultural, ética e legal que se refletem na falta de disponibilidade de órgãos para transplante.

Diante do avanço da medicina, atualmente são transplantados os órgãos (rim, coração, fígado, pulmão, intestino e pâncreas) e os tecidos (córnea, medula óssea, ossos e pele).

Os transplantes de tecidos e órgãos têm sido por longo tempo objetivo da pesquisa médica. ${ }^{3}$ Os primeiros casos de transplantes de um ser humano para outro foram de córneas e começaram a ser feitos por volta de 1880 . Os transplantes de órgãos começaram na década de 50 com transplantes de rim de gêmeos univitelinos para outro. A consagração do sucesso de rim transplantado veio em 1956 com o seguinte caso: Wando Foster deu um rim à irmã gêmea Edith Helen, ambos casados, com 21 anos, sem filhos.

Em 1967, o Dr. Christian Barnard realizou o primeiro transplante cardíaco de ser humano para ser humano. A este evento seguiuse o estabelecimento de programas de transplantes cardíacos no mundo inteiro. No Brasil, o pioneirismo deve-se ao Dr. Zerbini, do Hospital das Clínicas da Faculdade de Medicina da Universidade de São Paulo (FMUSP) que em 26 de maio de 1966 realizou o primeiro transplante de coração em João Ferreira da Cunha (João Boiadeiro), que sobreviveu 27 dias. O caso de sobrevivência mais longo no mundo de transplante de coração é o de Emmanuel Vitria, que viveu 18 anos com o coração jovem de um fuzileiro naval que morreu aos 20 anos, de um acidente de trânsito. ${ }^{6}$

A negativa da família em consentir a doação de órgãos é citada como o principal entrave na efetivação de transplante de órgãos. ${ }^{5}$

A doação é uma decisão da família, constituindo-se num momento difícil, embora tal ato represente a possibilidade de poder contribuir para que outras pessoas vivam; ao mesmo tempo em que se recebe a notícia da perda do familiar, sem ter tempo para internalizá-la, lhe é solicitada a decisão de doar órgãos. Emergem diferentes sentimentos como desespero, choro compulsivo, sentimentos de profunda tristeza, revolta, crença que haverá reversão da situação e até mesmo aceitação da perda, além do fato de que cada indivíduo/ família se ampara em princípios, valores, crenças diversas que lhe são próprias e que interferirão na decisão.

Em nenhum momento existe pressão para que a família concorde com a doação, mas lhe é respeitado o direito de decidir. $O$ fato de que a retirada de órgãos se faça com o doador em morte encefálica, traz dúvidas e incertezas, principalmente por retirar os órgãos enquanto o coração ainda bate.

Mediante a problemática que envolve a doação de órgãos, objetivouse neste estudo, conhecer a opinião do estudante universitário sobre a doação de órgãos.

\section{MÉTODOS}

Para atender o objetivo proposto, esta investigação trata-se de um estudo exploratório-descritivo, que consiste em investigações de pesquisa empírica, cuja principal finalidade é o delineamento ou a análise das características de fatos ou fenômenos, a avaliação de programas ou o isolamento de variáveis principais ou chave ${ }^{7}$.

$O$ estudo foi realizado em uma universidade privada de Fortaleza que funciona desde 21/03/73. Atualmente, oferece 23 cursos de graduação, distribuídos em quatro centros, entre eles, ciências da saúde, ciências tecnológicas, ciências jurídicas, ciências humanas e administração, sendo estes povoados por 15.178 alunos.

A população selecionada constituiu-se de estudantes universitários de ambos os sexos. A amostra foi aleatória, portanto, sendo constituída por 269 universitários, com idade entre 18 e 30 anos, independentemente do estado civil, religião, cor e que concordaram em participar da pesquisa.

Os dados foram coletados através de um questionário, durante três meses; organizados com auxílio do programa SPSS, analisados estatisticamente, representando-os em tabelas, fundamentados na literatura selecionada. Os depoimentos dos estudantes integraram os dados quantitativos, auxiliando na discussão.

Ressalta-se que esta pesquisa foi aprovada pelo Comitê de Ética da universidade supracitada e que os participantes foram esclarecidos sobre o anonimato, natureza e objetivos, e que poderiam retirar o consentimento no momento que o desejassem.

\section{RESULTADOS}

De acordo com a tabela 1, $187(70 \%)$ estudantes tinham idade entre 18 e 23 anos e 184 (68\%) eram mulheres. A maioria (78\%) era a favor da doação, independentemente da idade, porém com predomínio entre as mulheres, embora estas predominassem na amostra investigada. Cerca de $32(12 \%)$ eram indiferentes, e 27 $(10 \%)$ contrários à doação de órgãos.

Tabela 1 - Distribuição dos estudantes universitários segundo sexo, idade e posição em relação à doação de órgãos.

\begin{tabular}{|c|c|c|c|c|c|c|c|c|}
\hline \multirow{3}{*}{ Idade (anos) } & \multicolumn{3}{|c|}{ Masculino } & \multicolumn{2}{|c|}{ Feminino } & \multirow[b]{2}{*}{1} & \multicolumn{2}{|c|}{ Total } \\
\hline & $\mathrm{s}$ & $\mathrm{N}$ & 1 & $S$ & $\mathrm{~N}$ & & $n$ & $\%$ \\
\hline & & & & & & & & \\
\hline $18-23$ & 45 & 06 & 11 & 104 & 11 & 09 & 187 & 70 \\
\hline $24-29$ & 11 & 03 & 03 & 28 & 03 & 05 & 53 & 19 \\
\hline $30 \mathrm{ou}+$ & 04 & - & 01 & 17 & 04 & 03 & 29 & 11 \\
\hline Total & 61 & 09 & 15 & 149 & 18 & 17 & 269 & 100 \\
\hline
\end{tabular}

JBT J Bras Transpl 2005; 8:320-324 
De acordo com o quadro 1 , cerca de 233 (86,6\%) estudantes eram católicos; destes, $182(78,1 \%)$ estavam a favor da doação. Entre os protestantes, 25 (92,5\%) doariam seus órgãos, e aqueles (3,3\%) sem preferência religiosa, concordariam em ser doadores. Portanto, a maioria dos estudantes era favorável à doação, independentemente da idade ou da preferência religiosa. Quanto ao estado civil, 237 $(88,1 \%)$ eram solteiros; destes, $184(77,6 \%)$ concordariam em ser doadores. Entre os casados, 8,2\% eram a favor da doação. Então, a opção pela doação de órgãos, também independia do estado civil.

\begin{tabular}{|c|c|c|c|c|c|}
\hline \multicolumn{2}{|c|}{$\begin{array}{l}\text { Posição em } \\
\text { relação à doação }\end{array}$} & \multirow{2}{*}{$\frac{\text { Sim }}{182}$} & \multirow{2}{*}{$\begin{array}{r}\text { Não } \\
51\end{array}$} & \multirow{2}{*}{$\frac{n}{233}$} & \multirow{2}{*}{$\begin{array}{c}\% \\
86,6\end{array}$} \\
\hline Religião & Católico & & & & \\
\hline & Protestante & 25 & 0 & 27 & 10,0 \\
\hline & Sem religião & 09 & - & 09 & 3,3 \\
\hline & TOTAL & 216 & 53 & 269 & 100,0 \\
\hline \multicolumn{6}{|l|}{ Estado } \\
\hline \multirow[t]{3}{*}{ Civil } & Solteiro & 184 & 53 & 237 & 88,1 \\
\hline & Casado & 26 & 06 & 32 & 11,9 \\
\hline & TOTAL & 210 & 59 & 269 & 100,0 \\
\hline
\end{tabular}

Quadro 1 - Distribuição dos estudantes, segundo religião, estado civil e opinião em relação à doação de órgãos.

Os estudantes favoráveis à doação de órgãos justificaram sua posição como um ato de solidariedade que conduz à manutenção da vida, porém, havia a preocupação em relação ao cumprimento da lei que regulamenta a doação de órgãos. As justificativas estão ilustradas nas falas:

...depois da morte física de nada serve o corpo, então, por que não ajudar os que ainda permanecem vivos?..

...sou a favor, porque com a doação, devolvo a vida a alguém que, por doença, já não é capaz de viver sem um transplante...

...sou a favor, contanto que seja de forma justa, pois como tudo no mundo, existe diferença; pobre seria sempre doador e rico, receptor...

Os estudantes que se posicionaram contra a doação, receavam a venda de órgãos e o risco à vida dos doadores, como se pode perceber nas falas:

....a venda de órgãos para o exterior, falta de controle para onde e para quem vão esses órgãos...

...acredito que em algumas ocasiões são realizados procedimentos inadequados para que se apresse a doação...

....acho que o Brasil não tem regras suficientes para fazer isso sem enrolada, ou seja, irão matar pessoas doentes para pegarem seus órgãos...

Entre os motivos mais freqüentemente relacionados com recusa, incluem-se: apego emocional intenso ao corpo morto, não aceitação do diagnóstico de morte cerebral, incapacidade de tomar decisão, receio de comércio de órgãos, e desconhecimento sobre o aspecto legal da doação.

Os estudantes que se mostraram indiferentes à doação, justificaram- se por meio das falas:

...o Brasil é um País que, infelizmente, ainda há discriminação, quem está no final da lista de espera, nem sempre é favorecido...

...tenho que saber mais sobre o assunto, para dar uma resposta sincera...

...nem sou contra e nem sou favor, pois na hora da necessitar de um órgão, tudo vale...

Setenta e quatro estudantes $(27,5 \%)$ nada souberam informar sobre a doação de órgãos. Os depoimentos revelam este desconhecimento.

...gostaria de ter mais informações sobre o assunto...

...não sei quase nada, só sei que quem faz uma doação, depois da morte com certeza, terá o reino do céu...

Para 70 (26\%) participantes, a doação é opcional, fato demonstrado nas falas e 175 (65\%) declararam que não conheciam a lei que regulamenta o processo de doação.

...que alguns tipos de órgãos poderemos doar, ajudando a quem precisa...

...que é simples doar, basta colocar na carteira de identidade que é doador de órgãos...

Cerca de 62 (23\%) estudantes admitiram que a doação é um recurso para salvar vidas, conforme está evidenciado nos depoimentos:

...não sei muita coisa sobre doação, mas o pouco que sei é que eu, sendo uma doadora, posso salvar muitas vidas...

...os seres depois de mortos podem permanecer vivos se pelo menos um órgão seu estiver dando vida a outro...

Para 41 (15\%) estudantes, a doação significava uma maneira de ajudar ao próximo. Os depoimentos revelam este significado.

...na minha opinião ninguém deve ser contra, pois está se doando vida nova e cheia de felicidade para a família inteira...

...a doação de órgãos é um ato de solidariedade, para a pessoa que está precisando e você vai se achar uma pessoa que pode até salvar a vida de alguém...

Outros 20 (7,5\%) estudantes somente informaram que existe uma grande fila de espera, conforme ilustrado nas falas abaixo:

...o que sei é que existem muitas pessoas aguardando um dia, o início de uma nova vida...

...porque através de uma doação podemos dar esperança de dias melhores para alguém que fica anos na fila de espera...

Para dois $(0,7 \%)$ estudantes, a única informação que tinham era que havia um comércio de órgãos.

...Que existe um comércio ilegal...

...Porque no mundo de hoje, as coisas estão pelo avesso, pois o dinheiro fala mais alto. Pensei em ser doadora, mas minha família não concorda...

Para 197 (73\%) estudantes, o acesso às informações sobre doação de órgãos aconteceu através da televisão; 56 (21\%) por intermédio de amigos; 50 (18,5\%) foram informados por ocasião de campanhas; $28(10,5 \%)$ receberam informações procedentes de hospitais, e os demais (7\%) tiveram como fonte de informação, a família. 
Tabela 2 - Dúvidas sobre o processo doação de órgãos.

\begin{tabular}{lrr}
\hline DÚVIDAS & $\mathrm{n}$ & $\%$ \\
\hline Todas & 74 & 27,5 \\
Lei regulamentar & 138 & 51,3 \\
Órgãos que podem ser transplantados & 14 & 5,0 \\
Perfil do doador & 20 & 8,0 \\
Benefícios do transplante & 12 & 4,5 \\
Diagnóstico de morte encefálica & 11 & 4,0 \\
\hline TOTAL & 269 & $100 \%$ \\
\hline
\end{tabular}

De acordo com a tabela 2, 74 (27,5\%) estudantes relataram que nada sabiam sobre o processo de doação, e 138 (51,3\%) tinham dúvidas sobre a Lei regulamentar. Os demais eram desinformados sobre órgãos ou tecidos transplantados $(5 \%)$, perfil do doador $(8 \%)$, benefícios do transplante $(4,5 \%)$, e diagnóstico de morte cerebral $(4,0 \%)$.

A fim de ampliar o número de doadores de órgãos, os estudantes sugeriram como estratégias: campanhas $(53,5 \%)$; doação obrigatória (15\%); estrutura hospitalar adequada $(14,5 \%)$; aplicação rigorosa da Lei (12,5\%); incentivos financeiros (10,5\%); decisão de doação comprovada em documento $(10,0 \%)$. Os depoimentos ilustram as sugestões apresentadas:

...campanhas mais sérias, em televisão, rádios, jornais, revistas, etc. Principalmente, conscientização da população em geral...

...que fosse obrigatório para todo cidadão...

...que ficasse bem claras as regras do processo de doação, e que a coisa fosse séria e bem fiscalizada...

...como todo brasileiro é louco por dinheiro, poderia pagar uma taxa, para que doassem os órgãos após a morte...

\section{DISCUSSÃO}

A maioria das pessoas não fala sobre o desejo de doação em vida ou não comenta sobre a oposição à mesma, ficando indiferentes; portanto, a questão da doação vem a ser decidida pelos familiares.

O comportamento dos familiares em relação à doação de órgãos, segundo os estudantes, está condicionado a questões culturais e psicológicas, e há a tendência de familiares consentirem na doação quando bem orientados a respeito do conceito de morte encefálica $\mathrm{e}$ da finalidade humanística de doar. ${ }^{2}$ A cultura do povo brasileiro é ser extremamente solidário, facilitando, com isso, a doação de órgãos. ${ }^{8}$

A doação de órgãos é uma dádiva, pois tem o valor de conceder a vida novamente. Há uma conotação mística e religiosa nessa visão, porém é uma dádiva, na qual não se tem a liberdade de escolher e nem de conhecer o receptor. Dar-se sem saber se, realmente, foi aproveitado, ou se houve sucesso na doação. ${ }^{5}$

Para algumas famílias, a doação de órgãos pode ser um fator positivo em seu luto, pois há o conforto de saber que o seu ente querido está auxiliando outras pessoas. Porém, para outras famílias, esta hora de dor e sofrimento dificulta a tomada de decisão favorável, levandoas a optar pela não autorização à doação. Uma grande parcela da população brasileira não é suficientemente esclarecida para optar conscientemente pela não mutilação do seu cadáver e para seguir os trâmites burocráticos que lhe permitam tal opção ${ }^{9}$. No depoimento dos estudantes, percebe-se o impacto do desconhecimento sobre o processo de doação.

Observa-se o desconhecimento da Lei que regulamenta a doação de órgãos, inclusive das alterações que a sucederam, pois segundo o artigo 2, "as manifestações de vontade relativas à retirada post mortem de tecidos, órgãos e partes, constantes da Carteira de Identidade Civil e da Carteira Nacional de Habilitação, perderam sua validade a partir de 22 de dezembro de 2004'.

O motivo para doar é ajudar o outro, porém não deixa de ser acompanhado de dor por parte dos familiares, diante da perda do ente querido ${ }^{5}$. Os familiares vivenciam uma experiência de choque, descrença, sofrimento e confusão e mostram-se, de momento, incapazes de compreender e aceitar a realidade. Alguns familiares têm dificuldades por motivos religiosos e crenças pessoais, mas também por desconhecer a vontade do seu familiar diante da decisão de doar os próprios órgãos. Todavia, o sucesso na captação de órgãos depende das habilidades comunicativas dos profissionais de saúde ao relacionarem-se com os familiares de doadores.

O doador aparece como figura central no processo de doação, pois tudo remete a este: qualidades, papel familiar, ser benfeitor pela doação de órgãos. Os familiares questionam-se a respeito da possibilidade de provocar algum dano ao doador, quando autorizam a retirada dos órgãos. Mesmo que o doador o desejasse, autorizar a doação deixa marcas, porque não é possível ter a certeza de que essa, naquele momento, é a vontade da pessoa. Em algumas situações, os familiares não têm certeza absoluta a respeito da morte do doador ${ }^{5}$.

Em uma pesquisa sobre a vivência de doadores no processo de doação no transplante de fígado intervivos, foi evidenciado que ${ }^{10}$ os pais, mesmo conhecendo os riscos relacionados ao procedimento, manifestam o desejo de doar parte do fígado para o filho. A vontade de salvar a vida do filho é tão intensa que desconsideram os riscos a que estarão sendo submetidos na realização do transplante, não tendo dúvida quanto à decisão tomada. A batalha para encontrar uma solução é tão árdua que, quando a encontram, aceitam-na com facilidade, não tendo dificuldades na tomada de decisões quanto à escolha do tratamento e nem quanto a ser doadores. O desejo dos pais é salvar a vida do filho e amenizar o seu sofrimento e acreditam que, com a ajuda de Deus, conseguirão fazê-lo. Para as mães, o fato de serem mães lhes dá a convicção de doar parte do fígado para o filho, relacionando essa decisão com o renascimento do filho, com o "dar a vida novamente".

A fila de pessoas para o transplante de órgãos é demasiadamente imensa, devido à limitação de doadores. Os pacientes da fila de espera, conforme descrito pela literatura e observado no contato clínico, são pessoas severamente comprometidas do ponto de vista físico e que, ansiosamente, aguardam por uma resolução, sem tempo previsto, para um problema que lhes custa toda uma possibilidade de viver ${ }^{11}$.

Estima-se que anualmente, em todo o mundo, aproximadamente 500.000 pacientes desenvolvem insuficiência renal crônica; 300.000 , insuficiências cardíacas e 200.000, insuficiência hepática, 
resultando numa necessidade de transplante, apenas destes órgãos, de 1.000.000 por ano. Essas pessoas precisam da solidariedade de outras, que na maioria das vezes não têm esse sentimento nobre, por pura falta de conhecimento do assunto ${ }^{12}$.

Os depoimentos não só demonstram a desinformação, como a falta de credibilidade no cumprimento da Lei, na infra-estrutura, e na operacionalização do sistema de saúde responsável pelo processo de doação. Possivelmente, estes fatos sejam responsáveis pela escassez de órgãos doados e, conseqüentemente pelo aumento da lista de espera dos receptores.

Constatou-se que a televisão predominou como fonte informante, por ser um meio de comunicação em massa.

Diante das dúvidas referidas pelos pesquisados, seria oportuno sugerir que os centros transplantadores e comissões de captação de órgãos, em parceria com a central de transplantes, desenvolvessem um trabalho de conscientização sobre o processo de doação, utilizando os meios de comunicação em massa e as escolas públicas de ensino médio.

As sugestões apresentadas pelos pesquisados só vêm a corroborar com a comprovação do desconhecimento sobre a Lei específica confirmada anteriormente. Crê-se que seja necessária a realização de campanhas periódicas, objetivando a conscientização da população sobre a temática em vigor, acrescidas da inserção de um conteúdo transversal sobre doação de órgãos nas escolas públicas de ensino médio, pois estes estudantes atuariam como agentes multiplicadores destas informações junto às famílias e à comunidade.

\section{CONCLUSÕES}

Ao concluir este estudo, constata-se que há um desconhecimento significativo sobre o processo de doação de órgãos entre os estudantes universitários. O fato é preocupante, principalmente pelo pressuposto nível de esclarecimento dessa massa estudantil e pelo acesso facilitado às mais variadas fontes de informações. Então, provavelmente na sociedade em geral, o desconhecimento seja muito maior. Portanto, este fato corrobora para justificar a limitação de doação de órgãos.

Com base nos resultados desta pesquisa, seria procedente que a central de transplantes de cada Estado, em parceria com centros transplantadores, elaborasse e implementasse estratégias que visassem a conscientização da sociedade sobre a doação e transplante de órgãos, a fim de reduzir ou eliminar a lista de espera para transplantes.

Recomenda-se ainda que sejam incrementadas as comissões intrahospitalares para captação de órgãos, que as instituições sejam equipadas para a manutenção e distribuição dos órgãos doados, e que os profissionais da saúde sejam treinados para facilitar o processo de doação e a manutenção dos órgãos.

\section{ABSTRACT}

Objective: To be aware of the academic students' opinion on the organ donation. Method: Exploratory-descriptive study performed in a private university with 269 students with ages from 18 years old or older. Result: It was verified that the majority of students (70\%) were 18 to 23 years old. Students were predominantly female (68\%. It was observed that the majority of the researched sampling $(78 \%)$ revealed to be favorable to the organ donation, and $25 \%$ had doubts on the matter. As to the suggestions, $66 \%$ of the interviewed students indicated campaigns to achieve a better clarification on the subject and to make the whole population aware on the importance of the organ donation. Conclusion: It can be concluded that there was a significant non-familiarity by the investigated students on the organ donation process.

Keywords: organ and tissue donation, transplant legislation, opinion on the organ and tissue donation.

\section{REFERÊNCIAS}

1. Brasil. Lei. Nº 9.434 de 4 de fevereiro de 1997. Dispõe sobre a remoção de órgãos, tecidos parte do corpo humano para fins de transplante e tratamento e dá outras providências. Diário Oficial [da] República Federativa do Brasil. Brasília, 4 fev. 1997. Seção I, p. 191.

2. ABTO .Associação Brasileira de Transplantes de Órgãos. Registro Brasileiro de Transplantes. Ano IX. Edição anual. São Paulo, jan./dez. 2003, v. 2.

3. Pessini L, Barchifontaine CP. Problemas atuais de bioética. São Paulo: Loyola; 2000.

4. CAMPOS AH. Aumento do número de transplantes e da doação de órgãos e tecidos. Disponível em: <www.abto.com.br>. Acesso em: 12 jan. 2003.

5. Sadala MLA. A experiência de doar órgãos na visão de familiares de doadores. JBN. Bras. Nefrol., 2001; 23(3): 143-51.
6. CEARÁ. Manual de rotinas: doação de órgãos. Fortaleza: Secretaria Estadual da Saúde/SUS, 2001

7. Lakatos EM, Marconi MA. Metodologia do trabalho cientifico. São Paulo: Atlas, 1996.

8. Mesquita WP. Sociedade - Bio tecnologia Ciência e Desenvolvimento. Rev. 1998; 40-48.

9. Sabel H. Tributo à vida. Rev. SESC 1998; 30-35.

10. Hangai RK, Massarollo MCKB. Transplante de fígado intervivos: a vivência de doadores no processo de doação. JBT, 2004; 7: 220-222.

11. Hojaly EM, Romano BW. Modificação da imagem corporal ao longo do processo de transplante cardíaco. Rev. SOCESP 1995; 9-16.

12. Mendes GF. Doação de órgãos - consenso presumido. Rev. Jurídica 1998; 40-50. 